http://dx.doi.org/10.32929/2446-8355.2019v28n3p329-342

\title{
PRODUTIVIDADE, ÍNDICE DE VEGETAÇÃO E CLOROFILA DE TRIGO EM RESPOSTA À INOCULAÇÃO COM Azospirillum brasilense E ADUBAÇÃO NITROGENADA EM COBERTURA
}

\author{
André Mateus Prando ${ }^{1 *}$, Thiago Montagner Souza ${ }^{2}$, Adilson de Oliveira Junior ${ }^{1}$, \\ Claudemir Zucareli ${ }^{3}$
}

\footnotetext{
${ }^{1}$ Pesquisador, Empresa Brasileira de Pesquisa Agropecuária, Centro Nacional de Pesquisa de Soja (EmbrapaSoja), Londrina-PR. *E-mail do autor correspondente: andre.prando@embrapa.br.

${ }^{2}$ Pós-Doutorando em Fitotecnia, Departamento de Agronomia, Universidade Estadual de Londrina, LondrinaPR.

${ }^{3}$ Professor Adjunto, Departamento de Agronomia, Universidade Estadual de Londrina, Londrina-PR.
}

\section{Recebido: 10/12/2018; Aceito: 01/10/2019}

RESUMO: O objetivo foi avaliar os efeitos da inoculação de sementes de trigo (Triticum aestivum L.) com Azospirillum brasilense e doses de nitrogênio em cobertura no desempenho produtivo, índices de vegetação e clorofila e teores de nitrogênio na folha e no grão. Experimentos a campo foram conduzidos em delineamento experimental de blocos casualizados, esquema fatorial 2 x 5 com seis repetições. Avaliou-se a inoculação de sementes com Azospirillum brasilense (com e sem) e cinco doses de nitrogênio em cobertura (0, 30, 60, 90 e $120 \mathrm{~kg} \mathrm{ha}^{-1}$ ), aplicadas por ocasião do perfilhamento. Foram avaliados: produtividade e massa de mil grãos, teor de nitrogênio na folha e grão, massa seca da parte aérea, índice de clorofila e de vegetação avaliados por ocasião do perfilhamento, elongamento do colmo e espigamento. Os dados foram submetidos à análise de variância, correlação e análise de regressão para doses, e comparação de médias pelo teste de Tukey a 5\% para inoculação. $\mathrm{O}$ nitrogênio aplicado em cobertura no trigo cultivado após a soja não altera a produtividade, a massa de 1000 grãos e a massa seca da parte aérea, porém, o incremento das doses aumenta linearmente o teor de nitrogênio no grão e o índice de clorofila e de vegetação avaliado na fase de espigamento. A inoculação com Azospirillum brasilense aumenta o teor do nitrogênio no grão, mas não influencia as demais características avaliadas. $\mathrm{O}$ índice de vegetação por diferença normatizada (NDVI), avaliado no perfilhamento, elongamento do colmo e espigamento possui correlação positiva com a produtividade, quando avaliado no espigamento com o teor de nitrogênio da folha bandeira.

Palavras-chave: Triticum aestivum L. Rizobactérias. Nitrogênio. NDVI.

\section{PRODUCTIVITY, VEGETATION AND CHLOROPHY INDEX OF WHEAT IN RESPONSE TO INOCULATION WITH Azospirillum brasilense AND NITROGEN FERTILIZATION IN TOPDRESSING}

\begin{abstract}
The objective was to evaluate wheat inoculation with Azospirillum brasilense and nitrogen levels in top dressing on growth performance in vegetation and chlorophyll index and nitrogen content in the leaf and grain of wheat, grown in system tillage in soybeans
\end{abstract}


succession. The experiment was conducted on soil classified in soil classified as Typic Haplustox in Ponta Grossa, Paraná State, Brazil. The experimental design was a randomized block with six replications. We evaluated the inoculation of wheat seeds with Azospirillum brasilense (with and without) and five nitrogen levels (0,30,60, 90 and $\left.120 \mathrm{~kg} \mathrm{ha}^{-1}\right)$ applied at tillering. We evaluated: yield and thousand grain weight, leaf nitrogen content and grain, dry matter weight and vegetation and chlorophyll index evaluated at tillering, stem elongation and silking. Data were subjected to analysis of variance, correlation and regression analysis for doses and comparison of means by Tukey test at 5\% for inoculation. Nitrogen in top dressing in wheat grown after soybean does not change productivity, 1000 grain mass and dry matter mass, however, increase nitrogen levels increases linearly with nitrogen content in grain and chlorophyll and vegetation index evaluated at silking stage. The inoculation with Azospirillum brasilense Ab-V5 and Ab-V6 strain provides higher nitrogen content in grain but does not influence the other characteristics evaluated in the wheat crop. Normalized difference vegetation index (NDVI), measured at tillering, elongation stem and silking has positive correlation with wheat yield and, when NDVI is evaluated at silking with the nitrogen content of the flag leaf.

Key words: Triticum aestivum L. Rhizobacteria. Nitrogen. NDVI.

\section{INTRODUÇÃO}

O Brasil não é autossuficiente na produção de trigo, sendo comumente importada mais da metade da quantidade consumida. O potencial de produção nacional desse cereal é grande, mas em virtude da baixa rentabilidade e dos riscos de perdas durante a fase de produção, essa cultura vem perdendo área de cultivo para outras culturas (MINGOTI et al., 2014). Para reverter esse cenário faz-se necessário o desenvolvimento ou aprimoramento de tecnologias que possibilitem aumentar a produtividade ou reduzir os custos da lavoura ou, ainda, a combinação destes, visando a maior lucratividade da cultura.

A adubação corresponde ao maior custo da lavoura de trigo e dentre os nutrientes necessários o nitrogênio é o mais oneroso (COMPANIA NACIONAL DE ABASTECIMENTO - CONAB, 2018a). Portanto, o manejo correto deste nutriente pode aumentar a produtividade bem como contribuir para redução dos custos da lavoura. A consolidação do sistema de plantio direto, bem como o lançamento de novas cultivares, e tecnologias de produção demandam estudos contínuos para determinação de doses de nitrogênio adequadas ao cultivo nas diversas condições edafoclimáticas brasileiras.

Trabalhos de pesquisa têm sido realizados avaliando o efeito de níveis de nitrogênio em cobertura na cultura do trigo em sistema de semeadura direta, uma vez que os resultados obtidos são dependentes da cultura antecessora (VIOLA et al., 2013). As leguminosas além da fixação simbiótica de nitrogênio, possuem maior velocidade de decomposição da palhada com consequente mineralização de nutrientes, assim fornecem nitrogênio mineral para o trigo resultando em menor resposta ao nitrogênio que o cultivo após gramíneas (TEIXEIRA et al., 2014; MUS et al., 2016). 
Ronsani et al. (2018) avaliando a produção de forragem e de grãos de cultivares de trigo de duplo propósito em função de doses de nitrogênio sob a palhada de soja ( 0 a 120 ha $^{-1}$ ), observaram que independente do genótipo, o incremento das doses de nitrogênio apresentaram resposta linear positiva com todos os componentes de rendimento e massa seca da forragem. Entretanto, em condições de maior precipitação pluviométrica, o incremento de doses de nitrogênio pode reduzir a produtividade de grãos, devido ao aumento no acamamento de plantas (PRANDO et al., 2013).

Uma estratégia para substituir ou reduzir a necessidade de aplicação de alguns insumos químicos é o uso de bactérias promotoras de crescimento de plantas como o Azospirillum, que além de fixar nitrogênio atmosférico produz fitormônios que melhoram o crescimento radicular e, consequentemente, a absorção de água e de nutrientes, aumentando a tolerância a estresses hídricos e deixando as plantas mais vigorosas e produtivas (HUNGRIA, 2011; MUS et al., 2016). Entretanto, seu efeito na cultura está condicionado a uma série de fatores como modo de aplicação (FERREIRA et al., 2017) e interação com o ambiente. Segundo Piccinin et al. (2013), a aplicação de meia dose de nitrogênio associada à inoculação das sementes com Azospirillum brasilense promoveu resultados positivos no desempenho agronômico e na produtividade da cultura do trigo.

Trabalhos realizados com trigo em associação com Azospirillum evidenciaram que as bactérias se estabelecem na superfície externa da raiz para colonizar a rizosfera, confirmando a existência de uma interação estreita entre planta e bactéria fixadora (MAJEED et al., 2015; SOUZA; AMBROSINI; PASSAGLIA, 2015). Em trabalhos realizados por Hungria et al. (2010), nas condições brasileiras, observou-se que a utilização de Azospirillum brasilense proporcionou incremento médio de 13 a 18\% na produtividade do trigo. Contudo, nas respostas à inoculação deve-se considerar a interação dessa prática com diversos outros fatores, dentre eles a disponibilidade de nitrogênio via adubação.

O objetivo foi avaliar os efeitos da inoculação de sementes de trigo com Azospirillum brasilense combinado com doses de nitrogênio em cobertura $\left(0,30,60,90\right.$ e $\left.120 \mathrm{~kg} \mathrm{ha}^{-1}\right)$ no desempenho produtivo, nos índices de vegetação e clorofila e nos teores de nitrogênio na folha e no grão do trigo cultivado em semeadura direta em sucessão à soja.

\section{MATERIAL E MÉTODOS}

O experimento foi realizado na fazenda experimental do Escritório de Negócios da Embrapa Serviços Produtos e Mercado (SPM), localizada no município de Ponta Grossa, 25¹0'24' latitude Sul, 5004'32' longitude Oeste, com altitude de $870 \mathrm{~m}$. O solo do local é caracterizado como Latossolo Vermelho distrófico. O clima da região, segundo a classificação de Köppen, é Cfb, ou seja, clima temperado, temperatura média no mês mais frio abaixo de $18{ }^{\circ} \mathrm{C}$, com verões frescos, temperatura média no mês mais quente abaixo de $22{ }^{\circ} \mathrm{C}$ e sem estação seca definida.

A área experimental é manejada no sistema de plantio direto, sendo o trigo cultivado em sucessão à cultura da soja. Previamente à instalação dos experimentos, foi coletada amostra de solo da área experimental para análise química. Os resultados da amostra coletada na camada 
de 0-20 cm foram: $\mathrm{pH}\left(\mathrm{CaCl}_{2}\right): 4,74 ; \mathrm{C}: 18,94 \mathrm{~g} \mathrm{dm}^{-3} ; \mathrm{P}\left(\mathrm{Mehlich}^{-1}\right): 2,72 \mathrm{mg} \mathrm{dm}^{-3} ; \mathrm{H}+\mathrm{Al}$ : 2,43 cmolc dm ${ }^{-3} ; \mathrm{K}^{+}: 0,33$ cmolc dm${ }^{-3} ; \mathrm{Ca}^{2+}: 4,55 ; \mathrm{Mg}^{2+}: 2,00 \mathrm{cmolc} \mathrm{dm}^{-3}$; CTC: $9,31 \mathrm{cmolc}$ $\mathrm{dm}^{-3}$ e porcentagem de saturação por bases $(\mathrm{V}): 74 \%$. Os dados de temperatura média diária e precipitação pluvial durante o período de cultivo foram obtidos junto à estação meteorológica da Embrapa, localizada a aproximadamente $3 \mathrm{~km}$ do experimento e são apresentados na Figura 1.

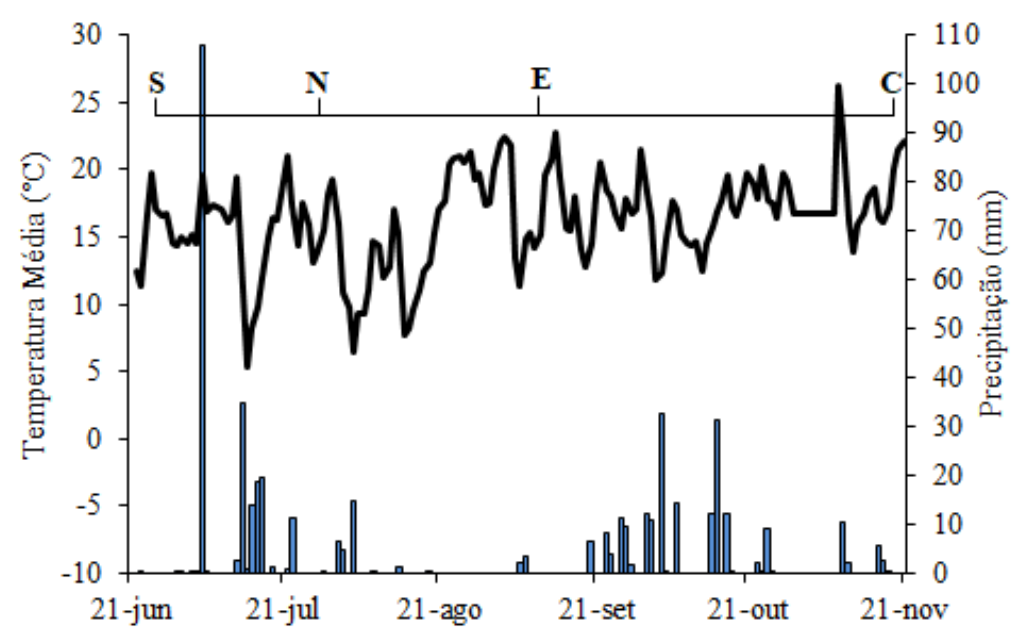

Figura 1. Temperatura média diária $\left({ }^{\circ} \mathrm{C}\right)$ e precipitação pluvial $(\mathrm{mm})$ em Ponta Grossa, PR, durante o desenvolvimento da cultura. S: semeadura, N: adubação nitrogenada de cobertura, E: espigamento, C: colheita. Daily average temperature $\left({ }^{\circ} \mathrm{C}\right)$ and rainfall precipitation ( $\mathrm{mm}$ ) in Ponta Grossa, PR, during the crop development. S: sowing, $N$ : nitrogen fertilization application in topdressing, E: heading, C: harvesting.

Fonte: Dados fornecidos pela Empresa Brasileira de Pesquisa Agropecuária (Embrapa). Data provided by the Brazilian Agricultural Research Corporation (Embrapa).

O delineamento experimental utilizado foi de blocos casualizados no esquema fatorial $2 \times 5$, com seis repetições. Avaliou-se o efeito da inoculação de sementes de trigo com Azospirillum brasilense (com e sem) e cinco doses de nitrogênio em cobertura (0, 30, 60, 90 e $\left.120 \mathrm{~kg} \mathrm{ha}^{-1}\right)$. A parcela experimental foi constituída por 22 linhas, espaçadas em $20 \mathrm{~cm}$, com seis metros de comprimento. Foi considerada como área útil da parcela experimental as 12 linhas centrais, desprezando-se 1,0 m nas extremidades, totalizando $9,6 \mathrm{~m}^{2}$ de área útil.

A adubação de semeadura com nitrogênio, fósforo e potássio (NPK) foi realizada conforme os resultados da análise química de solo, seguindo as indicações técnicas da Comissão Brasileira de Pesquisa de Trigo e Triticale para o Estado do Paraná. Foram utilizados $250 \mathrm{~kg} \mathrm{ha}^{-1}$ da fórmula (NPK) 8-28-16, correspondendo a $20 \mathrm{~kg} \mathrm{ha}^{-1} \mathrm{de} \mathrm{N}, 70 \mathrm{~kg} \mathrm{ha}^{-1} \mathrm{de}_{2} \mathrm{O}_{5}$ e $40 \mathrm{~kg} \mathrm{ha}^{-1} \mathrm{de} \mathrm{K}_{2} \mathrm{O}$.

O cultivar utilizado foi o BRS Tangará que possui ciclo médio (69 dias da emergência ao espigamento), altura média de $85 \mathrm{~cm}$ com moderada resistência ao acamamento, peso médio de mil sementes de $40 \mathrm{~g}$ e, pertence à classe comercial Trigo Melhorador tendendo a pão (BASSOI et al., 2010). As sementes utilizadas para implantação do experimento não foram tratadas com inseticida e/ou fungicida. Antes da semeadura, as sementes foram divididas em duas porções, sendo uma delas inoculada com líquido contendo 1 x $10^{8}$ células viáveis por $\mathrm{mL}$ da bactéria Azospirillum brasilense estirpes Ab-V5 e Ab-V6, na dose de $4 \mathrm{~mL}$ do produto comercial para cada kg de semente.

A semeadura foi realizada visando a obtenção de uma densidade de aproximadamente 300 
plantas por $\mathrm{m}^{2}$, com emergência de plântulas ocorrendo seis dias após a semeadura. A adubação de cobertura nas doses estipuladas foi realizada 28 dias após a emergência das plântulas, correspondendo ao início do perfilhamento, estádio 2 da escala de Feeks e Large (LARGE, 1954). A fonte de nitrogênio utilizada foi o nitrato de amônio, que contém $32 \% \mathrm{~N}$ e $3 \%$ de $\mathrm{K}_{2} \mathrm{O}$. O teor de potássio foi corrigido para que todas as parcelas recebecem a mesma quantidade do nutriente, independente da dose de nitrato de amônio aplicada. Quatro dias após a adubação de cobertura ocorreu precipitação pluvial de $6,4 \mathrm{~mm}$. Os tratos culturais foram realizados de acordo com as indicações técnicas da Comissão Brasileira de Pesquisa de Trigo e Triticale.

No início do florescimento foram coletadas ao acaso 30 folhas bandeira por parcela para determinação do teor de nitrogênio. As folhas foram secas em estufa de circulação de ar forçado até massa constante, com posterior moagem, digestão e destilação para determinar o teor de nitrogênio seguindo a metodologia 46-13.01 de micro kjedahl descrita por AACC International (AMERICAN ASSOCIATION OF CEREAL CHEMISTS INTERNATIONAL - AACC, 2000).

Previamente à colheita, foram coletadas plantas de duas linhas com $0,5 \mathrm{~m}$ de cada parcela, que foram secadas em estufa de circulação de ar e posteriormente pesadas para determinação da massa seca da parte aérea (MSPA), expressa em kg ha-1.

O índice de vegetação por diferença normalizada (NDVI - por sua abreviação em inglês de "Normalized Difference Vegetation Index") foi medido com o sensor portátil ótico ativo Green Seeker ${ }^{\circledR}$ (modelo 505 Handheld Sensor, NTech Industries ${ }^{\circledR}$, Ukiah, Estados Unidos da América), com dois tipos de LED ("ligth emitting diodes") que emitem radiação ativa em dois comprimentos de onda centralizados no vermelho $(660 \mathrm{~nm})$ e no infravermelho próximo $(770 \mathrm{~nm})$. As leituras foram realizadas a $0,80 \mathrm{~m}$ de altura do dossel da cultura, nas linhas centrais das parcelas na velocidade de aproximadamente $1 \mathrm{~m} \mathrm{~s}^{-1}$. As leituras do NDVI foram realizadas em três estádios fenológicos, segundo a escala de Feeks e Large (LARGE, 1954), sendo perfilhamento (estádio 3 perfilhos formados) elongação do colmo (estádio 6 - primeiro nó visível) e espigamento (estádio 10.3 - metade das espigas emergidas).

O índice de clorofila foi determinado com clorofilômetro (Modelo CFL1030, Falker ${ }^{\circledR}$, Porto Alegre, Brasil) que emite radiação no comprimento de onda de 470, 656 e $663 \mathrm{~nm}$. Foram realizadas duas leituras por parcela em folhas completamente expandidas, avaliadas em dois estádios fenológicos, segundo a escala de Feeks e Large (LARGE, 1954), elongação do colmo (estádio 6 primeiro nó visível) e espigamento (estádio 10.3 - metade das espigas emergidas).

A colheita foi realizada quando a cultura encontrava-se no estádio 11.4, correspondente à maturação de colheita (LARGE, 1954), aos 142 dias após a emergência das plântulas. Os grãos colhidos na área útil da parcela foram pesados para determinação do rendimento em $\mathrm{kg} \mathrm{ha}^{-1}$, corrigido a $13 \%$ de umidade. A massa de 1000 grãos foi determinada mediante média da pesagem de duas sub-amostras de 500 grãos de cada parcela. O teor de nitrogênio nos grãos também foi determinado seguindo a metodologia de microkjeldahl (método 46-13.01 da AACCI).

A análise exploratória dos dados foi realizada para verificar o atendimento das pressuposições da análise de variância. Os dados foram submetidos à análise de variância e análise de regressão para doses de nitrogênio em cobertura. As médias da inoculação foram comparadas pelo teste de Tukey a 5\% de significância. Os dados das características avaliadas também foram submetidos à análise 
de correlação de Pearson com o teor de nitrogênio foliar e a produtividade de grãos em trigo.

\section{RESULTADOS E DISCUSSÃO}

O resumo da análise de variância para as características avaliadas em resposta à inoculação, doses de nitrogênio em cobertura e a interação entre esses fatores é apresentado na Tabela 1. A interação entre a inoculação de sementes com Azospirillum e doses de nitrogênio em cobertura não foi significativa. A ausência de interação entre a rizobactéria e doses de nitrogênio foi observada também por Alves et al. (2017) no trigo, avaliando doses de nitrogênio entre 0-120 $\mathrm{kg} \mathrm{ha}^{-1}$ e sementes inoculadas com produto comercial $\left(2 \times 10^{8}\right.$ células viáveis por grama) na concentração de 4 gramas de inoculante para cada $\mathrm{kg}$ de semente, indicando que doses maiores não inibem a ação do Azospirillum.

Por outro lado, Piccinin et al. (2013) obtiveram interação significativa e, observaram aumento na produtividade, com a inoculação, mesmo em altas doses de fertilizante nitrogenado $\left(0-100 \mathrm{~kg} \mathrm{ha}^{-}\right.$ ${ }^{1}$ ). De acordo com Feldmann et al. (2018), a resposta à inoculação de sementes com Azospirillum brasilense está associada ao genótipo de trigo utilizado e ao baixo teor de matéria orgânica no solo da área experimental.

Tabela 1. Resumo da análise de variância (Prob. > F) para as características avaliadas em trigo, em função da inoculação de sementes com Azospirillum brasilense e doses de nitrogênio aplicadas em cobertura, em Ponta Grossa, PR. Summary of the analysis of variance (Prob.> F) for the characteristics evaluated in wheat, as a function of the inoculation of seeds with Azospirillum brasilense and nitrogen doses applied in topdressing, in Ponta Grossa, PR.

\begin{tabular}{lccccccccccc}
\hline FV & GL & MSPA & ICEL & ICES & NdviP & NdviEL & NdviES & N Foliar & N grão & MMG & Prod \\
\hline Bloco & 5 & 0,059 & 0,169 & 0,000 & 0,000 & 0,000 & 0,000 & 0,005 & 0,006 & 0,000 & 0,000 \\
Inoc. & 1 & 0,385 & 0,255 & 0,926 & 0,246 & 0,900 & 0,196 & 0,053 & $\mathbf{0 , 0 0 2}$ & 0,683 & 0,087 \\
Dose N & 4 & 0,640 & 0,939 & $\mathbf{0 , 0 0 0}$ & 0,324 & 0,900 & $\mathbf{0 , 0 0 1}$ & $\mathbf{0 , 0 0 0}$ & $\mathbf{0 , 0 0 0}$ & 0,567 & 0,071 \\
Inoc*N & 4 & 0,225 & 0,051 & 0,857 & 0,574 & 0,143 & 0,212 & 0,007 & 0,562 & 0,723 & 0,457 \\
\hline CV (\%) & & 9,12 & 3,33 & 2,71 & 9,47 & 5,36 & 7,83 & 3,06 & 1,85 & 4,24 & 8,93 \\
\hline
\end{tabular}

FV: Fonte de Variação; Inoc: inoculação com Azospirillum brasilense; N: Nitrogênio; CV (\%): Coeficiente de variação; GL: Graus de liberdade; MSPA: Massa seca de parte aérea; ICEL e ICES: índice de clorofila realizado no elongamento do colmo e espigamento, respectivamente; NdviP, NdviEL e NdviES: índice de vegetação realizado no perfilhamento, elongamento do colmo e espigamento, respectivamente; $\mathrm{N}$ foliar: teor de nitrogênio na folha bandeira; $\mathrm{N}$ grão: teor de nitrogênio no grão; MMG: Massa de mil grãos; Prod: Produtividade. $F V$ : Source of variation; Inoc: inoculation with Azospirillum brasilense; N: Nitrogen; CV (\%): Coefficient of variation; GL: Degrees of freedom; MSPA: Weight of dry shoot; ICEL and ICES: Chlorophyll index performed on the elongation of the stem and heading, respectively; NdviP, NdviEL and NdviES: Vegetation index in tillering, stem elongation and heading, respectively; $N$ foliar: Nitrogen content in the leaf; $N$ grain: nitrogen content in the grain; MMG: Weight one thousand grains; Prod: Productivity.

$\mathrm{O}$ índice de clorofila e de vegetação no espigamento apresentaram aumento linear com o incremento da adubação nitrogenada, conforme apresentado nas Figuras $2 \mathrm{~A}$ e 2B, respectivamente. As leituras realizadas antes do espigamento não foram influenciadas, possivelmente devido à baixa precipitação pluvial após a adubação nitrogenada, que atrasou a absorção de nitrogênio pela planta e, consequentemente, a diferenciação entre os tratamentos. 
O incremento das doses de nitrogênio não influenciou as demais características como massa de mil grãos e massa seca da parte aérea (Tabela 1). Esse resultado, é possivelmente, devido aos restos culturais da soja, juntamente com o teor de carbono orgânico do solo que é de $18,94 \mathrm{~g} \mathrm{dm}^{-3}$, e ainda a adubação de nitrogênio na base, que disponibilizaram nitrogênio inibindo os efeito negativos no desempenho produtivo do trigo. Além disso, o baixo volume de chuvas após a adubação nitrogenada na fase de perfilhamento e elongamento do colmo até o espigamento pode ter dificultado o aproveitamento da adubação nitrogenada pela planta (Figura 1).

A)
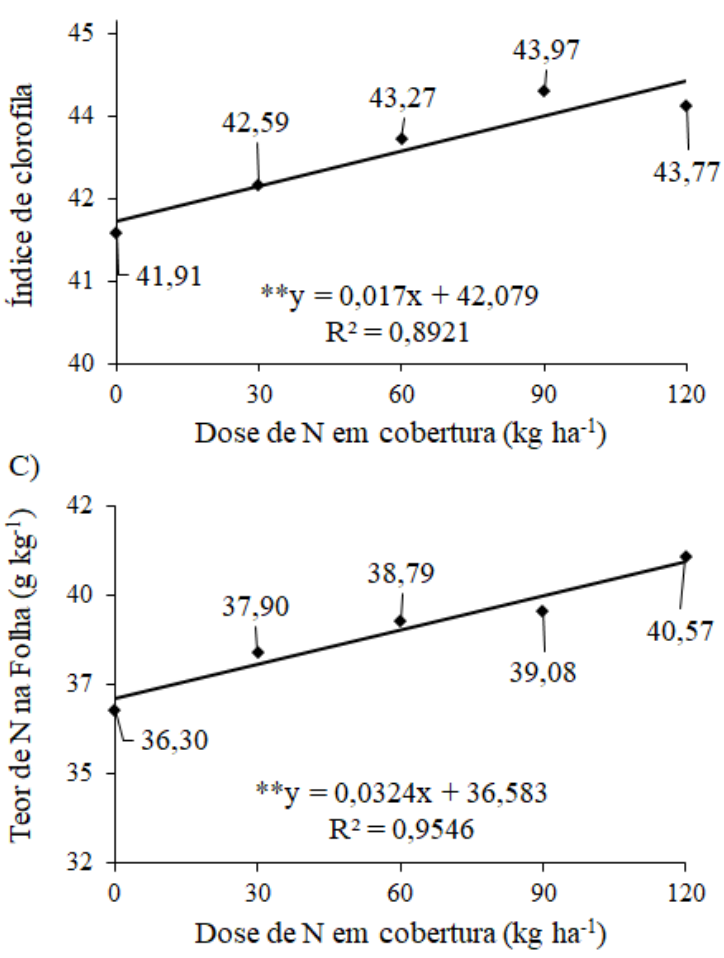

B)

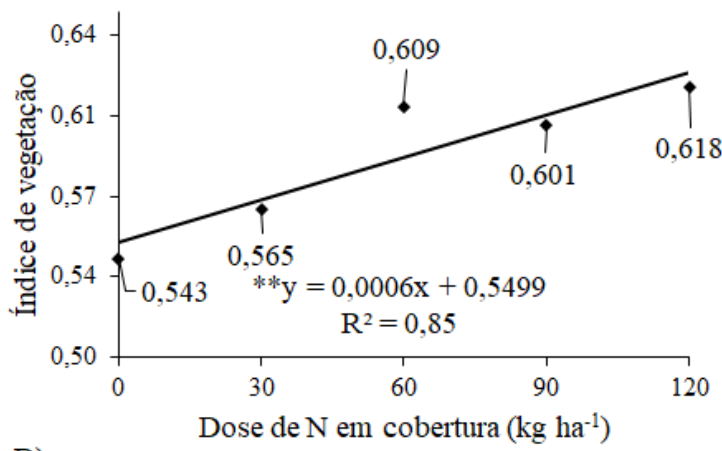

D)

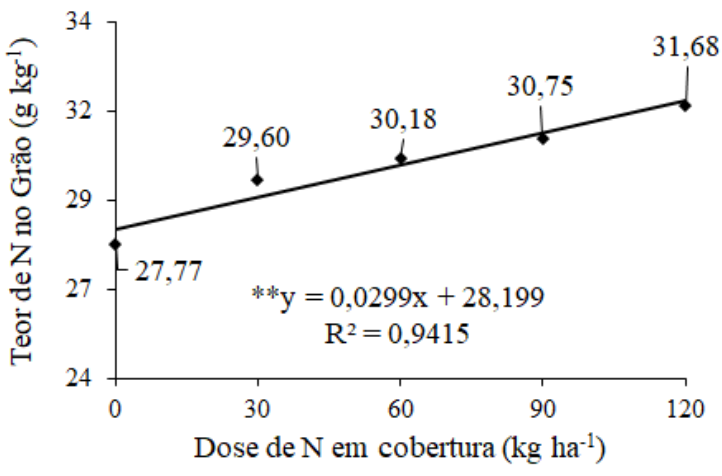

Figura 2. Índice de clorofila (A) e de vegetação (B) no espigamento, e teor de nitrogênio na folha bandeira (C) e no grão (D), avaliados em trigo em função de doses de nitrogênio aplicadas em cobertura, em Ponta Grossa, PR. * e ** significativo a $5 \%$ e a $1 \%$ pelo teste $\mathrm{t}$. Chlorophyll (A) and vegetation (B) index during crop heading stage, and nitrogen content in leaf $(C)$ and grain $(D)$, evaluated in wheat as a function of nitrogen doses applied in topdressing, in Ponta Grossa, PR. * and ** significant at 5\% and $1 \%$ by the t-test.

Segundo Trindade et al. (2006) a eficiência e/ou resposta dos genótipos de trigo a doses de nitrogênio depende da disponibilidade de água, pois a deficiência hídrica no solo limita a resposta da planta à aplicação de fertilizantes, retardando os processos envolvidos na nutrição mineral: difusão, fluxo de massa e interceptação pelas raízes.

Os teores de nitrogênio na folha bandeira e no grão aumentaram linearmente com o incremento de doses de nitrogênio em cobertura, conforme pode ser observado na Figura 2C e 2D, respectivamente. Esse resultado reflete a absorção de nitrogênio pela planta e translocação para o grão, no entanto sem influenciar a produtividade. O resultado observado corrobora com Souza et al. (2014) avaliando o efeito de doses crescentes de nitrogenio aplicadas em cobertura ( $\left(0-120 \mathrm{~kg} \mathrm{ha}^{-1}\right)$ no teor de nitrogênio dos grãos trigo cultivado em sucessão ao milho (quadrática) e à soja (linear).

O incremento de doses de nitrogênio não influenciou a produtividade de trigo (Tabela 1). Esse 
resultado deve-se, provavelmente, à relacão $\mathrm{C} / \mathrm{N}$ da palhada da soja que é baixa, apresenta rápida decomposição e, consequentemente, promove a mineralização de nitrogênio no solo, também ao teor de carbono orgânico do solo que é de $18,94 \mathrm{~g} \mathrm{dm}^{-3}$, com isso, aumenta a quantidade de nitrogênio disponível para a planta de trigo (REIS et al., 2011; ABBASI et al., 2015). Dessa forma, com base nos resultados observados, a adubação nitrogenada de cobertura pode ser reduzida ou dispensada em trigo cultivado após a soja. Segundo Garcia et al. (2013), a baixa eficiência na utilização de fertilizantes nitrogenados causa sérias mudanças ambientais que podem se intensificar, comprometendo a diversidade da vida no planeta, devido ao aumento no risco de contaminação da água por nitratos e da atmosfera por gases de efeito estufa.

Por outor lado, Teixeira Filho et al. (2010), Arenhardt et al. (2015) e Silva et al. (2015) obtiveram respostas positivas da produtividade de grãos à adubação nitrogenada de cobertura em cultivo em sucessão a leguminosas. No entanto, outros fatores como as condições edafoclimáticas, a quantidade de resíduo da cultura anterior e produtividade de grãos podem ter influenciado os resultados obtidos nesse estudo.

Durante o desenvolvimento da cultura do trigo, a precipitação total observada foi de $445 \mathrm{~mm}$ distribuídos durante ao longo do ciclo (Figura 1), atendendo a necessidade hidrica da cultura que é estimada em 300 mm (FORNASIERI-FILHO, 2008). Porém, após a adubação nitrogenada de cobertura não ocorreram grandes volumes de precipitação pluvial (Figura 1), o que ter atrasado e dificultado a absorção e aproveitamento de nitrogênio pela planta. Contudo, neste cultivo, a produtividade média foi de $3.758 \mathrm{~kg} \mathrm{ha}^{-1}$, acima da produtividade média nacional agricola que foi de $2.736 \mathrm{~kg} \mathrm{ha}^{-1}$ e do Paraná que foi de $2.891 \mathrm{~kg} \mathrm{ha}^{-1}$, obtidas no mesmo ano agrícola de condução do experimento (CONAB, 2018b).

A inoculação com Azospirillum brasilense estirpes Ab-V5 e Ab-V6 não influenciou a maioria das características avaliadas na cultura do trigo, com exceção do teor de nitrogênio nos grãos que foi 2,1\% maior com utilização de sementes inoculadas (Tabela 1 e 2). Assim como também observado por Silva e Pires (2017), a inoculação de sementes de trigo com A. brasilense não alteram o rendimento de grãos uma vez que as condições de cultivo não foram limitantes para o desenvolvimento da cultura, ausência de deficiências hídrica e nutricional.

Em trabalho realizado por Galindo et al. (2017) avaliando o efeito da inoculação com diferentes estirpes de Azospirillum brasilense observaram incrementos médios de 18,6\% (2014) e 19,6\% (2015) na produtividade do trigo com a aplicação de 150 e $100 \mathrm{~kg}$ de nitrogenio por hectare, respectivamente. Porém, neste trabalho não se observou diferença significativa na produtividade do trigo com a inoculação das sementes (Tabela 2). Fukami et al. (2016) destacam que a substituição total da adubação nitrogenada pela inoculação pode não ser viável, contudo, em alguns casos a inoculação permite uma redução de cerca de $25 \%$ do $\mathrm{N}$ a ser aplicado na cultura.

Em trabalho realizado por Sayed et al. (2015), a inoculação com 30 x $10^{6}$ unidades formadoras de colônias de Azospirillum estirpe HM1 em vasos de $2 \mathrm{~kg}$ contendo plantas de trigo, resultou em maior elongação da raiz $(+52 \%)$ e da superfície total de raízes frescas de plântulas $(+277 \%)$, em relação ao controle sem inoculação, aplicando apenas $50 \%$ do total de fertilizante nitrogenado. Segundo os autores, a aplicação de $100 \%$ do fertilizando nitrogenado inibiu a elongação das raizes proporcionada pela inoculação dos microorganismos. Okon e Labandera-Gonzales (1994), avaliando os resultados obtidos por pesquisadores em 20 anos de pesquisas em diferentes regiões do mundo, e 
diversas culturas, observaram que 60 a $70 \%$ dos experimentos proporcionaram incrementos na produtividade devido à inoculação com Azospirillum, com aumentos estatisticamente significativos na ordem de 5 a 30\%. Segundo os autores, o principal fator que influencia a resposta positiva é a concentração do inoculante e a viabilidade da bactéria em colonizar as raízes.

Tabela 2. Valores médios das características avaliadas em trigo, em função da inoculação de sementes com Azospirillum brasilense, em Ponta Grossa, PR. Mean values of the characteristics evaluated in wheat as a function of the inoculation of seeds with Azospirillum brasilense, in Ponta Grossa, PR.

\begin{tabular}{|c|c|c|c|c|c|c|c|c|c|c|}
\hline Semente & $\begin{array}{l}\text { MSPA } \\
\mathrm{kg} \mathrm{ha}^{-1}\end{array}$ & $\begin{array}{c}\text { ICEL } \\
-\end{array}$ & $\begin{array}{c}\text { ICE } \\
-\end{array}$ & $\begin{array}{c}\text { NdviP } \\
-\end{array}$ & $\begin{array}{c}\text { NdviEL } \\
-\end{array}$ & $\begin{array}{c}\text { NdviES } \\
-\end{array}$ & $\begin{array}{c}\text { N Foliar } \\
\mathrm{g} \mathrm{kg}^{-1}\end{array}$ & $\begin{array}{c}\text { N grão } \\
\text { g kg-1 }^{-1}\end{array}$ & $\begin{array}{c}\text { MMG } \\
\mathrm{g}\end{array}$ & $\begin{array}{c}\text { Prod } \\
\mathrm{kg} \mathrm{ha}^{-1}\end{array}$ \\
\hline Inoculada & $8.498 \mathrm{a}$ & $31,72 \mathrm{a}$ & $43,11 \mathrm{a}$ & $0,327 \mathrm{a}$ & $0,515 \mathrm{a}$ & $0,595 \mathrm{a}$ & $38,22 \mathrm{a}$ & $30,31 \mathrm{a}$ & $39,9 \mathrm{a}$ & $3.682 \mathrm{a}$ \\
\hline Controle & $8.324 \mathrm{a}$ & $32,04 \mathrm{a}$ & $43,09 \mathrm{a}$ & $0,337 \mathrm{a}$ & $0,514 \mathrm{a}$ & $0,579 \mathrm{a}$ & 38,83 a & $29,69 \mathrm{~b}$ & $39,7 \mathrm{a}$ & $3.834 \mathrm{a}$ \\
\hline DMS & 399 & 0,55 & 0,61 & 0,016 & 0,014 & 0,024 & 0,61 & 0,36 & 0,88 & 175 \\
\hline Média & 8.412 & 31,88 & 43,10 & 0,332 & 0,515 & 0,587 & 38,53 & 30,00 & 39,8 & 3.758 \\
\hline
\end{tabular}

Médias seguidas por letra diferente na coluna diferem entre si pelo teste de Tukey a 5\% de significância. DMS: Diferença média significativa; MSPA: Massa seca de parte aérea; ICEL e ICES: índice de clorofila realizado no elongamento do colmo e espigamento, respectivamente; NdviP, NdviEL e NdviES: índice de vegetação realizado no perfilhamento, elongamento do colmo e espigamento, respectivamente; $\mathrm{N}$ foliar: teor de nitrogênio na folha bandeira; N grão: teor de nitrogênio no grão; MMG: Massa de mil grãos; Prod: Produtividade. Means followed by different letter in the column differ from each other by the Tukey test at 5\% significance. DMS: significant mean difference; MSPA: Weight of dry shoot; ICEL and ICES: Chlorophyll index performed on the elongation of the stem and heading, respectively; NdviP, NdviEL and NdviES: Vegetation index in tillering, stem elongation and heading, respectively; $N$ foliar: Nitrogen content in the leaf; $N$ grain: nitrogen content in the grain; MMG: Weight of one thousand grains; Prod: Productivity.

Tabela 3. Correlação de Pearson (r) da produtividade e teor foliar de N com as características avaliadas na cultura do trigo, em Ponta Grossa, PR. Pearson correlation ( $r$ ) of productivity and $N$ contente in the leaf with the characteristics evaluated in the wheat crop, in Ponta Grossa, PR.

\begin{tabular}{lccccccccc}
\hline & MSPA & ICEL & ICE & NdviP & NdviEL & NdviES & N Foliar & N grão & MMG \\
\hline Prod & $0,20^{\mathrm{ns}}$ & $0,17^{\mathrm{ns}}$ & $-0,03^{\mathrm{ns}}$ & $0,40^{* *}$ & $0,34^{* *}$ & $0,39^{* *}$ & $0,41^{* *}$ & 0,06 & $0,36^{* *}$ \\
N Foliar & $-0,08^{\mathrm{ns}}$ & $0,21^{\mathrm{ns}}$ & $0,30^{*}$ & $0,08^{\mathrm{ns}}$ & $0,18^{\mathrm{ns}}$ & $0,37^{* *}$ & 1 & $0,56^{* *}$ & $0,26^{*}$ \\
\hline
\end{tabular}

${ }_{\text {ns }}^{* *} \mathrm{e}^{*}$ : Não significativo e significativo ao nível de 1 e $5 \%$ de significância, pelo teste t. MSPA: Massa seca de parte aérea; ICEL e ICES: índice de clorofila realizado no elongamento do colmo e espigamento, respectivamente; NdviP, NdviEL e NdviES: índice de vegetação realizado no perfilhamento, elongamento do colmo e espigamento, respectivamente; $\mathrm{N}$ foliar: teor de nitrogênio na folha bandeira; $\mathrm{N}$ grão: teor de nitrogênio no grão; MMG: Massa de mil grãos; Prod: Produtividade. ${ }^{n s}$, ** and $*$ : Not significant and significant at the 1 and 5\% level of significance, by the t test. MSPA: Weight of dry shoot; ICEL and ICES: Chlorophyll index performed on the elongation of the stem and heading, respectively; NdviP, NdviEL and NdviES: Vegetation index in tillering, stem elongation and heading, respectively; $N$ foliar: Nitrogen content in the leaf; $N$ grain: nitrogen content in the grain; MMG: Weight of one thousand grains; Prod: Productivity.

O índice de clorofila avaliado no elongamento do colmo e no espigamento não apresentou correlação significativa com a produtividade do trigo (Tabela 3). Contudo, o índice de clorofila avaliado no espigamento apresentou correlação de $0,30 \mathrm{com}$ o teor de nitrogênio na folha bandeira (Tabela 3). O que se explica devido ao papel do nitrogênio na síntese da clorofila. Theago et al. (2014) também observaram correlação positiva entre a concentração de nitrogênio nas folhas e as 
leituras do clorofilômetro, avaliado aos 68 dias após a emergencia quantos as plantas se encontravam no estádio de florescimento ( $r>0,50)$. No entanto, o clorofilômetro considera apenas a planta avaliada e não o conjunto de plantas e sua biomassa, como ocorre com o índice de vegetação.

A massa de mil grãos apresentou correlação de Pearson positiva de 0,36 com a produtividade de grãos (Tabela 3), demonstrando a importância deste componente na produtividade da cultura. $\mathrm{O}$ teor de nitrogênio na folha bandeira apresentou correlação de 0,41 , e o índice de vegetação por diferença normatizada (NDVI) avaliado no perfilhamento, elongamento do colmo e espigamento apresentou correlação significativa de 0,40; 0,34 e 0,39, respectivamente, com a produtividade. Além disso, o NDVI avaliado no espigamento apresentou correlação significativa de 0,37 com o teor de nitrogênio da folha bandeira. Esses resultados demonstram que o NDVI proporcionou uma boa avaliação do estado nutricional da planta com a vantagem de ser uma avaliação rápida, não destrutiva e que resulta um indicativo precoce do potencial produtivo da cultura. Isso indica que o NDVI pode ser utilizado para diferenciar níveis de produtividade, ou que pode ser utilizado para a adubação de cobertura a taxa variável. Corroborando Silva e Pires (2017) que também observaram que a avaliação de NDVI apresenta-se como ferramenta útil para predição do rendimento de grãos em trigo.

\section{CONCLUSÃO}

O nitrogênio em cobertura no trigo cultivado após a soja não altera a produtividade, a massa de 1000 grãos e a massa seca da parte aérea, porém, o incremento das doses aumenta linearmente o teor de nitrogênio no grão, o índice de clorofila e de vegetação avaliados no espigamento.

A inoculação com Azospirillum brasilense estirpes Ab-V5 e Ab-V6 aumenta o teor do nitrogênio no grão do trigo, mas não influencia as demais características avaliadas na cultura.

O índice de vegetação por diferença normatizada (NDVI) avaliado no perfilhamento, elongamento do colmo e espigamento possui correlação positiva com a produtividade do trigo e, quando avaliado no espigamento, com o teor de nitrogênio da folha bandeira.

\section{AGRADECIMENTOS}

Os autores agradecem ao Conselho Nacional de Desenvolvimento Científico e Tecnológico (CNPq), em associação com o Ministério da Agricultura, Pecuária e Abastecimento (MAPA), e à Coordenação de Aperfeiçoamento de Pessoal de Nível Superior (CAPES) pelo apoio financeiro.

\section{REFERÊNCIAS BIBLIOGRÁFICAS}

AMERICAN ASSOCIATION OF CEREAL CHEMISTS INTERNATIONAL - AACC International. Crude Protein - Micro-Kjeldahl. Approved Methods of Analysis, 11th Ed. Method 46-13.01. St. Paul, MN, U.S.A.: AACC International, 1999. Disponível em: http://methods.aaccnet.org/summaries/46-13-01.aspx. Acesso em: 25 nov. 2018.

ABBASI, M. K.; TAHIR, M. M.; SABIR, N.; KHURSHID, M. Impact of the addition of different plant residues on nitrogen mineralization-immobilization turnover and carbon 
content of a soil incubated under laboratory conditions. Solid Earth, Gottingen, v. 6, n. 1, p.197-205, 2015. Disponível em: https://www.solid-earth.net/6/197/2015/se-6-197-2015.pdf. Acesso em: 10 dez. 2018.

ALVES, C. J.; ARF, O.; RAMOS, A. F.; GALINDO, F. S.; NOGUEIRA, L. M.; RODRIGUES, R. A. Irrigated wheat subjected to inoculation with Azospirillum brasilense and nitrogen doses as top-dressing. Revista Brasileira de Engenharia Agrícola e Ambiental, Campina Grande, v. 21, n. 8, p.537-542, 2017. Disponível em: http://www.scielo.br/pdf/rbeaa/v21n8/1415-4366-rbeaa-21-08-0537.pdf. Acesso em: 10 dez. 2018.

ARENHARDT, E. G.; SILVA, J. A. G.; GEWEHR, E.; OLIVEIRA, A. C.; BINELO, M. O.; VALDIERO, A. C.; GZERGORCZICK, M. E.; LIMA, A. R. C. The nitrogen supply in wheat cultivation dependent on weather conditions and succession system in southern Brazil. African Journal of Agricultural Research, v. 10, n. 48, p.4322-4330, 2015. Disponível em: https://academicjournals.org/journal/AJAR/article-full-text-pdf/126CDF056169. Acesso em: 10 dez. 2018.

BASSOI, M. C.; RIEDE, C. R.; CAMPOS, L. A. C.; TAVARES, L. C. V; SHIOGA, P. S.; MIRANDA, L. C.; SCHOLZ, M. B. S.; BECKERT, O. P.; OKUYAMA, L. A.; MACHADO, J. C.; SCHEEREN, P. L.; POLA, J. N.; SERA, G. S. MIRANDA, M. Z.; AZAMBUJA, J. R. S.; DENGLER, R. U. Cultivares de trigo Embrapa e Iapar. Londrina: Embrapa Soja, 2010. 60 p. Disponível em: https://www.infoteca.cnptia.embrapa.br/infoteca/bitstream/doc/856640/1/Documentos321.pdf . Acesso em: 25 nov. 2018.

COMPANIA NACIONAL DE ABASTECIMENTO - CONAB. Planilhas de custos de produção - culturas de inverno. Brasília, DF, 2018. Disponível em: https://www.conab.gov.br/info-agro/custos-de-producao/planilhas-de-custo-deproducao/itemlist/category/403-planilhas-de-custos-de-producao-culturas-de-inverno. Acesso em: 26 out. 2018 a.

COMPANIA NACIONAL DE ABASTECIMENTO - CONAB. Série histórica das safras: trigo. Brasília, DF, 2018. Disponível em: https://www.conab.gov.br/info-agro/safras/seriehistorica-das-safras?start=30. Acesso em: 26 out. 2018 b.

FELDMANN, N. A.; BREDEMEIER, C.; HAHN, L.; MÜHL, F. R. Wheat cultivars submitted to seed inoculation with Azospirillum brasilense and nitrogen application in different environments. Científica, Jaboticabal, v. 46, n. 1, p.95-100, 2018. Disponível em: http://cientifica.org.br/index.php/cientifica/article/view/1028/633. Acesso em: 10 dez. 2018.

FERREIRA, J. P.; NUNES, R. F.; SILVA, R. B.; DAL BEM, E. A.; GARCIA, D. P.; SABUNDJIAN, M. T.; DE SOUZA, F. M. L. Azospirillum brasilense via foliar e doses de nitrogênio em cobertura na cultura do trigo na região de itapeva-sp. Revista Brasileira de Engenharia de Biossistemas, Tupã, v. 11, n. 2, p.154-163, 2017. Disponível em: http://seer.tupa.unesp.br/index.php/BIOENG/article/view/516/328. Acesso em: 10 dez. 2018.

FORNASIERI FILHO, D. Manual da cultura do trigo. Jaboticabal: Funep, 2008. 338 p. 
FUKAMI, J.; NOGUEIRA, M. A.; ARAUJO, R. S.; HUNGRIA, M. Accessing inoculation methods of maize and wheat with Azospirillum brasilense. AMB Express, Münster, v. 6, n. 3, p.1-13, 2016. Disponível em: https://link.springer.com/article/10.1186/s13568-015-0171-y. Acesso em: 10 dez. 2018.

GALINDO, F. S.; TEIXEIRA-FILHO, M. C. M.; BUZETTI, S.; SANTINI, J. M. K.; ALVES, C. J.; LUDKIEWICZ, M. G. Z. Wheat yield in the Cerrado as affected by nitrogen fertilization and inoculation with Azospirillum brasilense. Pesquisa Agropecuária Brasileira, Brasília, v. 52, n. 9, p.794-805, 2017. Disponível em: http://www.scielo.br/pdf/pab/v52n9/1678-3921-pab-52-09-00794.pdf. Acesso em: 10 dez. 2018.

GARCIA, G.; CARDOSO, A. A.; SANTOS, O. A. M. Da escassez ao estresse do planeta: um século de mudanças no ciclo do nitrogênio. Química Nova, São Paulo, v. 36, n. 9, p.14681476, 2013. Disponível em: http://www.scielo.br/pdf/qn/v36n9/32.pdf. Acesso em: 10 dez. 2018.

HUNGRIA, M. Inoculação com Azospirillum brasilense: inovação em rendimento a baixo Custo. Londrina: Embrapa Soja, 2011. 36 p. Disponível em: https://www.embrapa.br/en/busca-de-publicacoes/-/publicacao/879471/inoculacao-comAzospirillum-brasilense-inovacao-em-rendimento-a-baixo-custo. Acesso em: 26 out. 2018b.

HUNGRIA, M.; CAMPO, R. J.; SOUZA. E. M.; PEDROSA, F. O. Inoculation with selected strains of Azospirillum brasilense and A. lipoferum improves yields of maize and wheat in Brazil. Plant Soil, Crawley, v. 331, n. 1-2, p.413-425, 2010. Disponível em: https://link.springer.com/article/10.1007/s11104-009-0262-0. Acesso em: 10 dez. 2018.

LARGE, E. C. Growth stages in cereals illustration of the Feeks scales. Plant Pathology, Oxford, v. 3, n. 4, p.22-24, 1954. Disponível em: https://bsppjournals.onlinelibrary.wiley.com/doi/abs/10.1111/j.1365-3059.1954.tb00716.x. Acesso em: 10 dez. 2018.

MAJEED, A.; ABBASI, M. K.; HAMEED, S.; IMRAN, A.; RAHIM, N. Isolation and characterization of plant growth-promoting rhizobacteria from wheat rhizos phere and their effect on plant growth promotion. Frontiers in Microbiology, Lausanne, v. 6, p.1-10, 2015. Disponível em: https://www.ncbi.nlm.nih.gov/pmc/articles/PMC4362341/pdf/fmicb-0600198.pdf. Acesso em: 10 dez. 2018.

Mingoti, R.; HOLleR, W. A.; SPADOTTO, C. A. Produção potencial de trigo no Brasil. Campinas: Embrapa Gestão Territorial, 2014. 2 p. Disponível em: https://www.alice.cnptia.embrapa.br/bitstream/doc/978795/1/SGTEInformativo02.pdf.

Acesso em: 26 out. 2018.

MUS, F.; CROOK, M. B.; GARCIA, K.; COSTAS, A. G.; GEDDES, B. A.; KOURI, E. D.; PARAMASIVAN, P.; RYU, M.; OLDROYD, G. E. D.; POOLE, P. S.; UDVARDI, M. K.; VOIGT, C. A.; ANÉ, J.; PETERS, J. W. Symbiotic nitrogen fixation and challenges to extending it to non-legumes. Applied Environmental Microbiology, Columbia, v. 82, n. 13, p.3698-3710, 2016. Disponível em: https://aem.asm.org/content/aem/82/13/3698.full.pdf. Acesso em: 10 dez. 2018. 
OKON, Y.; LABANDERA-GONZALEZ, C. A. Agronomic applications of Azospirillum: an evaluation of 20 years worldwide field inoculation. Soil Biology and Biochemistry, Elmsford, v. 26, n. 12, p.1591-1601, 1994. Disponível em: https://www.sciencedirect.com/science/article/abs/pii/0038071794903115. Acesso em: 10 dez. 2018.

PICCININ, G. G.; BRACCINI, A. L.; DAN, L. G. M.; BAZO, G.L.; HOSSA, K. R.; PONCE, R. M. Rendimento e desempenho agronômico da cultura do trigo em manejo com Azospirillum brasilense. Revista Agrarian, Dourados, v. 6, n. 22, p.393-401, 2013. Disponível em: http://ojs.ufgd.edu.br/index.php/agrarian/article/view/1931/1588. Acesso em: 10 dez. 2018.

PRANDO, A. M.; ZUCARELLI, C.; FRONZA, V.; OLIVEIRA, F. A.; OLIVEIRA JÚNIOR, A. Características produtivas do trigo em função de fontes e doses de nitrogênio. Pesquisa Agropecuária Tropical, Goiânia, v. 43, n. 1, p.34-41, 2013. Disponível em: http://www.scielo.br/pdf/pat/v43n1/09.pdf. Acesso em: 10 dez. 2018.

REIS, W. P.; BALIZA, D. P.; RESENDE, P. M., ALBUQUERQUE, A. D.; PASSOS, A. M. A.; BOTREL, E. Comparação de sistemas de cultivo (Plantio Direto e Convencional) e de cultivares de trigo, em sucessão à soja. Revista de Agricultura, Piracicaba, v. 86, n. 1, p.8396, 2011. Disponível em: http://www.fealq.org.br/ojs/index.php/revistadeagricultura/article/view/83/pdf_2797. Acesso em: 10 dez. 2018.

RONSANI, S. C.; PIVA, J. T.; FIOREZE, S. L.; BASSO, K. C.; RIBEIRO, R. H.; BESEN, M. R. Adubação nitrogenada na produção de grãos e matéria seca de cultivares de trigo de duplo propósito. Revista de Ciências Agroveterinárias, Lages, v. 17, n. 1, p.174-181, 2018. Disponível em: http://www.revistas.udesc.br/index.php/agroveterinaria/article/view/9530/pdf. Acesso em: 10 dez. 2018.

SAYED, E.; HAMEDA, E. A.; ALTHUBIANI, A. S. Enhancement of plant growth by soil inoculation with Azospirillum brasilense HM1 isolated from soil of Saudi Arabia. International Journal of Current Microbiology Applied Sciences, Tamilnadu, v. 4, n. 10, p.238-248, 2015. Disponível em: https://www.ijcmas.com/vol-410/El\%20Sayed,\%20Hameda\%20E.\%20A.\%20and\%20Althubiani,\%20Abdullah\%20S..pdf. Acesso em: 10 dez. 2018.

SILVA, J. A. G.; ARENHARDT, E. G.; KRÜGER, C. A. M. B.; LUCCHESE, O. A.; METZ M.; MAROLLI, A. A expressão dos componentes de produtividade do trigo pela classe tecnológica e aproveitamento do nitrogênio. Revista Brasileira de Engenharia Agrícola e Ambiental, Campina Grande, v. 19, n. 1, p.27-33, 2015. Disponível em: http://www.scielo.br/pdf/rbeaa/v19n1/1807-1929-rbeaa-19-01-0027.pdf. Acesso em: 10 dez. 2018.

SILVA, S. R.; PIRES, J. L. F. Resposta do trigo BRS Guamirim à aplicação de Azospirillum, nitrogênio e substâncias promotoras do crescimento. Revista Ciência Agronômica, Fortaleza, v. 48, n. 4, p.631-638, 2017. Disponível em: http://www.scielo.br/pdf/rca/v48n4/1806-6690-rca-48-04-0631.pdf. Acesso em: 10 dez. 2018. 
SOUZA, R. D.; AMBROSINI, A.; PASSAGLIA, L. M. P. Plant growth-promoting bacteria as inoculants in agricultural soils. Genetics and Molecular Biology, Ribeirão Preto, v. 38, n. 4, p.401-419, 2015. Disponível em: http://www.scielo.br/pdf/gmb/v38n4/1415-4757-gmbS1415-475738420150053.pdf. Acesso em: 10 dez. 2018.

SOUZA, T. M.; PRANDO, A. M.; TAKABAYASHI, C. R.; SANTOS, J. S.; ISHIKAWA, A. T.; FELÍCIO, A. L. S. M.; ITANO, E. N.; KAWAMURA, O.; ZUCARELI, C.; HIROOKA, E. Y. Composição química e desoxinivalenol em trigo da região Centro - Sul do Paraná: Adubação nitrogenada em cobertura associada com Azospirillum brasilense. Semina: Ciências Agrárias, Londrina, v. 35, n. 1, p.327-342, 2014. Disponível em: https://www.redalyc.org/articulo.oa?id=445744139027. Acesso em: 10 dez. 2018.

TEIXEIRA, R. A.; SOARES, T. G.; FERNANDES, A. R.; BRAZ, A. M. S. Grasses and legumes as cover crop in no-tillage sustem in northeastern Pará Brazil. Acta Amazonica, Manaus, v. 44, n. 4, p.411-418, 2014. Disponível em: http://www.scielo.br/pdf/aa/v44n4/02.pdf. Acesso em: 10 dez. 2018.

TEIXEIRA-FILHO, M. C. M.; BUZETTI, S.; ANDREOTTI, M.; ARF, O.; BENETT, C. G. S. Doses, fontes e épocas de aplicação de nitrogênio em trigo irrigado em plantio direto. Pesquisa Agropecuária Brasileira, Brasília, v. 45, n. 8, p.797-804. 2010. Disponível em: http://www.scielo.br/pdf/pab/v45n8/v45n8a04.pdf. Acesso em: 10 dez. 2018.

THEAGO, E. Q.; BUZETTI, S.; TEIXEIRA-FILHO, M. C. M.; ANDREOTTI, M.; MEGDA, M. M.; BENETT, C. G. S. Doses, fontes e épocas de aplicação de nitrogênio influenciando teores de clorofila e produtividade do trigo. Revista Brasileira de Ciência do Solo, Viçosa, p.1826-1835, 2014. Disponível em: http://www.scielo.br/pdf/rbcs/v38n6/a17v38n6.pdf. Acesso em: 10 dez. 2018.

TRINDADE, M. G.; STONE, L. F.; HEINEMANN, A. B.; CÃNOVAS, A. D.; MOREIRA, J. A. A. Nitrogênio e água como fatores de produtividade do trigo no cerrado. Revista Brasileira de Engenharia Agrícola e Ambiental, Campina Grande, v. 10, n. 1, p.24-29, 2006. Disponível em: http://www.scielo.br/pdf/\%0D/rbeaa/v10n1/v10n1a04.pdf. Acesso em: 10 dez. 2018.

VIOLA, R.; BENIN, G.; CASSOL, L. C.; PINNOW, C.; FLORES, M. F.; BORNHOFEN, E. Adubação verde e nitrogenada na cultura do trigo em plantio direto. Bragantia, Campinas, v. 72, n. $1, \quad$ p.90-100, 2013. Disponível em: http://www.scielo.br/pdf/brag/v72n1/aop_1654_13.pdf. Acesso em: 10 dez. 2018. 